\title{
Factor structure and validity of the Alcohol Use Disorders Identification Test (AUDIT) in a sample of mentally disordered offenders
}

\author{
Patrick Hallinan $^{\mathrm{a}}$, Sinead McGilloway ${ }^{\mathrm{a} *}$, Martin Dempster $^{\mathrm{b}}$ and \\ Michael Donnelly ${ }^{\mathrm{c}}$ \\ ${ }^{a}$ Department of Psychology, National University of Ireland, Maynooth, Ireland; \\ ${ }^{b}$ Department of Psychology, Queen's University Belfast, Belfast, UK; ${ }^{c}$ Centre for \\ Public Health, School of Medicine, Dentistry and Biomedical Sciences, Queen's \\ University Belfast, Belfast, UK
}

(Received 7 July 2010; final version received 14 July 2011)

Investigations of the factor structure of the Alcohol Use Disorders Identification Test (AUDIT) have produced conflicting results. The current study assessed the factor structure of the AUDIT for a group of Mentally Disordered Offenders (MDOs) and examined the pattern of scoring in specific subgroups. The sample comprised 2005 MDOs who completed a battery of tests including the AUDIT. Confirmatory factor analyses revealed that a two-factor solution - alcohol consumption and alcohol-related consequences - provided the best data fit for AUDIT scores. A three-factor solution provided an equally good fit, but the second and third factors were highly correlated and a measure of parsimony also favoured the two-factor solution. This study provides useful information on the factor structure of the AUDIT amongst a large MDO population, while also highlighting the difficulties associated with the presence of people with mental health problems in the criminal justice system.

Keywords: Mentally Disordered Offenders (MDOs); Alcohol Use Disorders Identification Test (AUDIT); factor analysis; diversion and liaison scheme

\section{Introduction}

The Alcohol Use Disorders Identification Test (AUDIT) was first developed by the World Health Organisation (WHO), six-country project tasked with identifying a concise, psychometrically valid and multi-culturally sensitive instrument designed to identify individuals with alcohol problems (Babor, de la Fuente, Saunders, \& Grant, 1992). The result was a 10-item, self-report questionnaire which is purported to assess three conceptual domains

\footnotetext{
*Corresponding author. Email: Sinead.McGilloway@nuim.ie
} 
(Appendix 1) including alcohol consumption, alcohol dependence and alcohol-related problems (Saunders, Aasland, Babor, De La Fuente, \& Grant, 1993). Unlike most other alcohol screening instruments, the AUDIT is designed to identify people with hazardous alcohol consumption before dependence or permanent harm has occurred (Saunders et al., 1993). In other words, it indicates risky or hazardous drinking which may highlight likely dependence, although it is not sufficient to provide a definitive diagnosis of alcohol dependence per se. Researchers exploring the factor structure of the AUDIT have used a wide variety of statistical methods which, to date, have produced divergent results. For example, both a single factor (El-Bassel, Schilling, Ivanoff, Chen, \& Hanson, 1998; Skipsey, Burleson, \& Kranzler, 1997) and two and three factor structures (Doyle, Donovan, \& Kivlahan, 2007; Gmel, Heeb, \& Rehm, 2001; Karno, Granholm, \& Lin, 2000; Lima et al., 2005; Maisto, Conigliaro, McNeil, Kraemer, \& Kelly, 2000; Medina-Mora, Carreno, \& De la Fuente, 1998; O'Hare \& Sherrer, 1999; Rist, Glöckner-Rist, \& Demmel, 2009; Shevlin \& Smith, 2007; Shields, Guttmanova, \& Caruso, 2004) have been identified as the most suitable data fit across populations of varying characteristics. Thus, the application of different types of methods across a range of populations has led to a diverse pool of findings in this area.

The data for the current study were collected as part of a larger evaluation of a Belfast-based police liaison scheme which, in line with established UK policy (Reed, 1992), was developed to identify and assess Mentally Disordered Offenders (MDOs - offenders with a mental health problem or learning disability) and direct them away from the Criminal Justice System (CJS) towards health and social care services. The nature and extent of alcohol misuse amongst defendants within the CJS has been well documented and this population is unique in that they tend to be repeatedly characterised by drunkenness and alcohol misuse upon arrest (e.g. Brabins \& Travers, 1994; Kerner, Weitekamp, Stelly, \& Thomas, 2006). However, less is known about the precise patterns of alcohol consumption among MDOs. An analysis of the current data, after the first 18 months of the scheme, showed a distribution of markedly high AUDIT scores with $68 \%$ (226/331) of MDOs reporting harmful alcohol use (cutoff $\geq 8$ ) (McGilloway \& Donnelly, 2004). A survey of a similar diversion service in the Birmingham Court showed that 22\% (109/504) were identified as alcohol dependent (Hillis, 1993), as were $14 \%$ in a survey of a liaison scheme in a remand prison in Birmingham (O'Brien \& Forman, 1994).

The principal aim of this study was to analyse the factor structure of the AUDIT (Saunders et al., 1993) for all those MDOs who were assessed as part of the local scheme during a 7-year period. Secondary objectives were to obtain information on the reliability and construct validity of the AUDIT and to examine patterns of alcohol consumption in this population. This provided a unique opportunity to produce normative data for the AUDIT 
and test its dimensional structure with a large, non-clinical sample of MDOs with consumption levels considerably higher than would be seen in the general (community-based) population.

\section{Method}

\section{Participants and settings}

The MDOs in this study ( $n=2005$ ) were assessed during 1998-2004 as part of the Belfast-based liaison scheme and all of the information was subsequently entered onto a large anonymised database. The Custody Record Forms (CRFs) of all detainees were closely examined, in the first instance, by two Community Mental Health Nurses (CMHNs) who were qualified in Forensic Health Care and who had completed a 6-week induction course prior to joining the scheme. The CRFs were screened for evidence of: (1) a history of mental illness and/or learning disability; (2) an 'odd' crime; (3) a violent crime and (4) unusual behaviour leading to referral by the police (McGilloway \& Donnelly, 2004). Everyone who met one or more of the above criteria was approached by the CMHN when in police custody or, occasionally, on first appearance at the local Magistrates Court, and asked if they would like to participate in an assessment. The nurses may also be required, on request, to assess remand prisoners or people who appear at the police station without being formally arrested.

The two nurses consult with the custody sergeant and/or the Forensic Medical Officer (FMO), where necessary, to verify the presence of one or more of the above criteria. These criteria are based on those used previously in the Birmingham Court Diversion service (on which the Belfast-based service was modelled) (McGilloway \& Donnelly, 2004) and have been used successfully during both the early implementation and continuation phases of the service during the first seven years. In order to be included in this substudy, all participants were also required to have fully completed the AUDIT and all those who were teetotallers were excluded. Of the original 2509 offenders assessed as part of the scheme, 11\% $(n=273)$ did not complete the AUDIT correctly (i.e. failed to answer one or more of the questions as shown by a frequency analysis) whilst $9 \%(n=231)$ were teetotallers, thereby yielding a final sample size of 2005 and an overall completion rate of $80 \%$.

\section{Measures}

The AUDIT was administered by one of the two CMHNs as part of a battery of measures designed to assess overall mental health status and risky behaviour including: depression, psychosis, learning disability, drug misuse and dangerous behaviour. For example, the 18-item Brief Psychiatric Rating Scale (BPRS) (Overall \& Gorham, 1962) was used to assess the nature and 
extent of severe psychiatric symptomatology; the nurses received training in BPRS administration and joint rating sessions undertaken during the pilot indicated good agreement between them. A Profile Form was also used to elicit background information including: sociodemographic data; primary diagnosis; institutional history; current and previous offence(s); police and court 'disposal'; and follow-up service(s). The CMHNs provided help, as and when required, to any offenders who had difficulty completing the selfreport AUDIT (e.g. for reasons of literacy).

The AUDIT consists of 10 forced-response questions with either a three or five-point Likert scale format. There are seven frequency items (items 1, 3-8), one quantity item (item 2) and two 'yes, but not in the last year' and 'yes, in the last year' response formats (items 9 and 10). Scores range from 0 to 40 in order of increasing severity (Appendix 1). The cut-off score of $\geq 8$ is recommended as an indication of hazardous drinking behaviour, whilst a score of $\geq 10$ provides greater specificity, but less sensitivity (Saunders et al., 1993). Saunders et al. (1993) suggest that the AUDIT consists of three factors including 'alcohol consumption' (items 1-3), 'alcohol dependence' (items 4-6) and 'alcohol-related problems' (items 7-10). Following a pilot study and in the interests of simplicity and brevity, some very minor changes were made to the wording on AUDIT items 1, 2, 4, 5 and 10, but with care not to affect the meaning of the questions or integrity of the questionnaire in any way.

\section{Factor analyses}

A confirmatory factor analysis was chosen as the most suitable means of examining the proposed factor structure of the AUDIT because it is commonly used to explore competing existing dimensional structures (e.g. Doyle et al., 2007; Rist et al., 2009; Shevlin \& Smith, 2007). Three confirmatory factor models were specified and estimated using LISREL 8.80 (Jöreskog \& Sörbom, 2006) - a one-factor model, a two-factor model and a three-factor model. To account for the ordinal level of measurement of the items, a polychoric correlation matrix and an asymptotic covariance matrix were computed, based on the 10 items of the AUDIT, and the model parameters estimated using weighted least squares (as recommended by Jöreskog \& Sörbom, 2001, pp. 240-243). In the case of the two-factor and three-factor models, all factors were allowed to correlate and no correlated errors were included in any of the models.

Following the guidelines suggested by Hoyle and Panter (1995), the goodness-of-fit for each model was assessed using a range of fit indices including the Satorra-Bentler scaled chi-square $\left(\mathrm{S}-\mathrm{B} \chi^{2}\right)$, the Adjusted Goodness of Fit Index (AGFI: Tanaka \& Huba, 1989), and the Comparative Fit Index (CFI: Bentler, 1990). For the CFI, values $>.95$ are considered to reflect an acceptable model fit (Hu \& Bentler, 1999). 
Model fit is better when values of the chi-square statistic are smaller and values of the AGFI are greater, with an AGFI value of 1 indicating a perfect fit. In addition, the Root Mean Square Error of Approximation (RMSEA: Steiger, 1990) with $90 \%$ confidence intervals $(90 \% \mathrm{CI})$ was reported, where a value $<.05$ indicates close fit, whilst values up to .08 indicate reasonable errors of approximation in the population (Jöreskog \& Sörbom, 1993). The standardised root mean square residual (SRMR: Jöreskog \& Sörbom, 1981) has been shown to be sensitive to model mis-specification and its use is recommended by $\mathrm{Hu}$ and Bentler (1999). Values <.08 are considered to be indicative of acceptable model fit (Hu \& Bentler, 1998). The comparative fit of the models was also assessed using the Parsimony Goodness of Fit Index (PGFI: Mulaik et al., 1989), an index used for purposes of model comparison, which takes into account the number of parameters being estimated, with the largest value (closest to 1) indicating the best fitting model.

\section{Results}

\section{Profile of participants}

Participants were typically male (83\%), Caucasian (99\%), single (67\%) and in their early 30 s $(M=31$ years, $\mathrm{SD}=9.7$, range $13-70)$. Almost $90 \%$ $(1764 / 1983)$ were unemployed whilst $21 \%(413 / 2005)$ were homeless. The most commonly reported diagnoses included unspecified neurotic and manic depression $(36 \%, 667 / 1867)$, unspecified alcohol disorder $(21 \%, 392 / 1867)$, personality disorder $(9 \%, 172 / 1867)$ and schizophrenia $(7 \%, 123 / 1867)$. These diagnoses were assigned by the CMHNs, sometimes in consultation with the FMO based at the station. The CMHNs also received an unspecified amount of support from a forensic psychiatrist. Most of the current offences were acquisitive in nature $(29 \%, 554 / 1914)$, offences against the person $(17 \%, 335 / 1914)$, or of a miscellaneous nature $(16 \%, 299 / 1914)$; these crime categorisations were based on those used in the Birmingham diversion service. A self-report measure revealed that alcohol was involved in 68\% (1364/1914) of recorded current offences (i.e. the offender was influenced by alcohol during the perpetration of the crime).

\section{AUDIT analysis}

\section{Descriptive statistics and scale reliability}

The average total score for the AUDIT was $20.2(\mathrm{SD}=11.7, \min =1$, $\max =40)$. Most participants obtained scores at both the recommended $(\geq 8)(80 \%, 1606 / 2005)$ and higher $(\geq 10)$ thresholds $(74 \%, 1494 / 2005)$. The average total score when teetotallers $(n=231)$ were included was 18.14 . The Cronbach's alpha value of .94 indicated a high level of internal 
consistency and, therefore, very good reliability of the scale with this particular sample.

A number of parametric tests were conducted using SPSS (version 13.0) (SPSS Inc.) to investigate patterns of scoring on the AUDIT within certain subgroups. Firstly, males obtained a significantly higher mean score $(M=20.7, \mathrm{SD}=11.6)$ than females $[M=17.9, \mathrm{SD}=11.7, t(1994)=3.97$, $p<.005$ ], although the effect size (Cohen's $d=.24$ ) was small (Cohen, 1992). We also found that participants who were homeless $(M=23.4, \mathrm{SD}=11.3)$ scored significantly higher than their non-homeless counterparts $[M=19.4$, $\mathrm{SD}=11.6, t(2003)=6.23, p<.005$, Cohen's $d=.34]$, whilst those whose offences involved alcohol $(M=22.9, \mathrm{SD}=10.7)$, obtained higher mean scores than offenders without such a history $[M=14.1, \mathrm{SD}=11.4$, $t(1913)=16, p<.005$ ] and with a large effect size (Cohen's $d=.8$ ). In addition, a one-way between groups ANOVA showed that those who had a history of psychiatric hospitalisation obtained significantly lower scores $(M=13.07, \mathrm{SD}=9.55)$ than those with a penal/prison background $(M=23.53, \mathrm{SD}=11.5) ;[F(5,1958)=29.24, p<.0005$, mean difference $=10.46, p=.008$, Cohen's $d=.08]$. The other groups included in this analysis were 'care background' $(M=21.69, \mathrm{SD}=11.74)$, 'mental health hospital' $(M=20, \mathrm{SD}=10.49)$, 'other' $(M=15.3, \mathrm{SD}=10.28)$ and 'not known' $(M=18.76, \mathrm{SD}=10.28)$.

\section{Factorial validity}

The suitability of the data for factor analysis was assessed by various means. Firstly, an inspection of the correlation matrix showed strong correlations between most of the items (ranging from .39 to .91) with almost every correlation exceeding .5. Given the evidence of substantial inter-item relationships, there were reasonable grounds for a factor analysis to explore any potential item groupings (Pallant, 2005). Table 1 shows the frequency (and \%) of answers to each AUDIT item; these results show that this sample of MDOs had an unusually high endorsement of many of the items including, for example, the frequency with which they were drinking and the number of drinks per day. (Comparison data are provided later in the Discussion.)

The fit indices for all three models are reported in Table 2. For all models, the chi-square value is large and statistically significant and the RMSEA values also indicate poor fitting models. However, the CFI and SRMR suggest that all models fit the data well. Overall, most of the fit indices show that the three-factor model provides the best fit of the data, although the two-factor model is more parsimonious.

Modification indices were examined to determine if any logical adjustments could be made to the model to improve the fit. For all models, it was clear that a large improvement in fit could be obtained by specifying a covariance in the error terms of items 9 and 10 . When this path was added to 


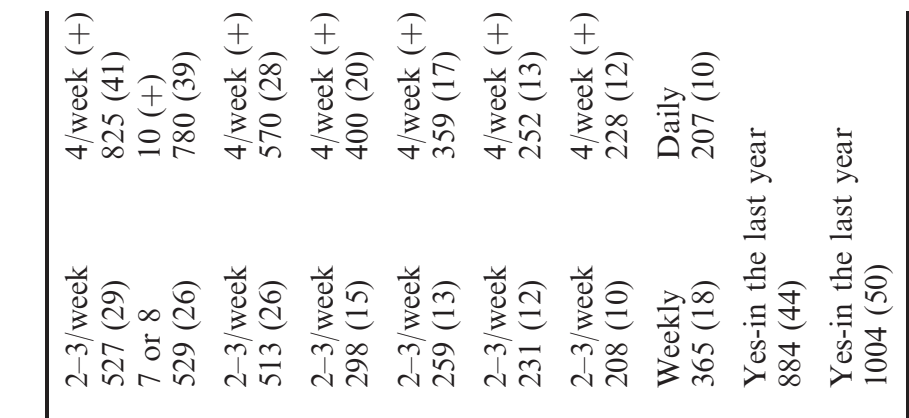

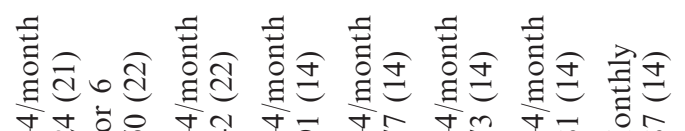

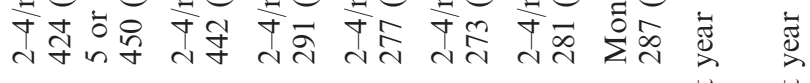

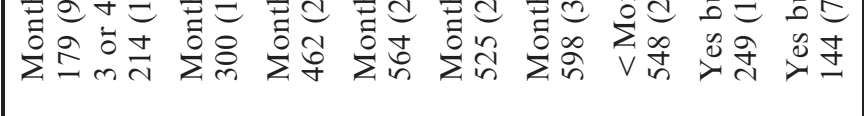

$$
\begin{aligned}
& \text { ڤ્气 }
\end{aligned}
$$

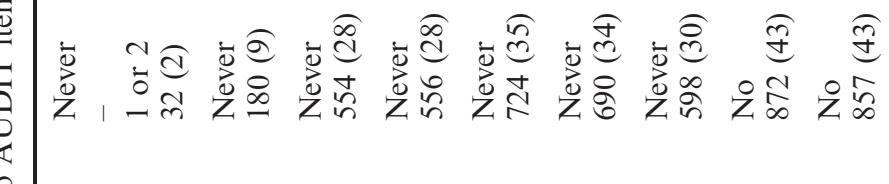

$$
\begin{aligned}
& \circ \\
& \text { : } \\
& \text { क्षे } \\
& \text { tั }
\end{aligned}
$$

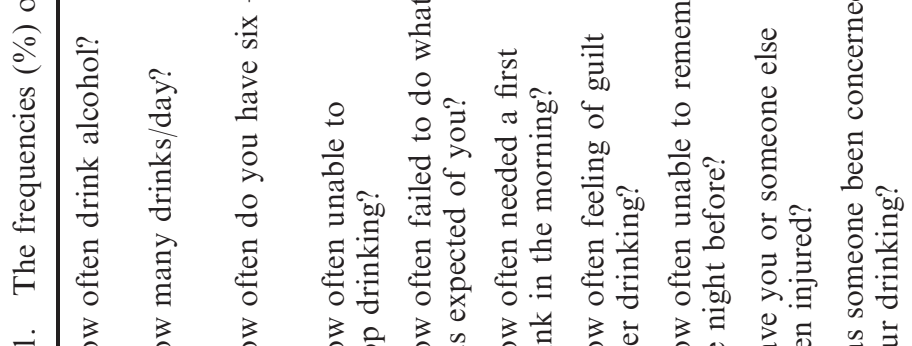

$$
\begin{aligned}
& \frac{\tilde{D}}{\Xi}
\end{aligned}
$$

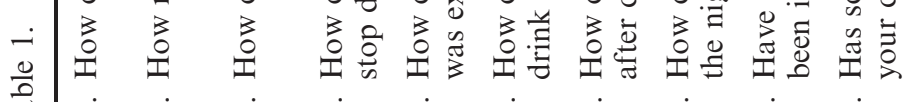

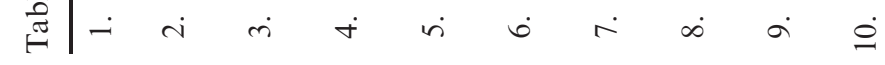


the model, the fit indices improved (Table 3). Again, the two-factor and three-factor models were superior to the one-factor model on all the fit indices. In this case, the RMSEA, CFI and SRMR values coincided to show that the two- and three-factor models provided an adequate fit of the data. There was little difference between these two models; the latter fitted slightly better although the former proved to be more parsimonious.

Table 4 presents the factor loadings for the one-, two- and three-factor models, respectively. All factor loadings were moderate to large in value

Table 2. Fit indices for hypothesised models.

\begin{tabular}{lccc}
\hline & One-factor model & Two-factor model & Three-factor model \\
\hline S-B $\chi^{2}(\mathrm{df})$ & $1109.78(35), p<.001$ & $739.90(34), p<.001$ & $644.51(32), p<.001$ \\
RMSEA & $.12(.12, .13)$ & $.10(.095, .11)$ & $.098(.091, .10)$ \\
$\quad(90 \% \mathrm{CI})$ & .98 & .99 & .99 \\
CFI & .062 & .059 & .056 \\
SRMR & .56 & .66 & .68 \\
AGFI & .46 & .49 & .47 \\
PGFI & .46 & \\
\hline
\end{tabular}

Table 3. Fit indices for hypothesised models with additional error covariance between items 9 and 10 .

\begin{tabular}{lccc}
\hline & One-factor model & Two-factor model & Three-factor model \\
\hline S-B $\chi^{2}(\mathrm{df})$ & $668.19(34), p<.001$ & $361.52(33), p<.001$ & $303.43(31), p<.001$ \\
RMSEA & $.096(.09, .10)$ & $.070(.064, .077)$ & $.066(.060, .073)$ \\
$\quad(90 \% \mathrm{CI})$ & & .99 & .99 \\
CFI & .99 & .032 & .032 \\
SRMR & .037 & .77 & .79 \\
AGFI & .65 & .52 & .50 \\
PGFI & .48 & & \\
\hline
\end{tabular}

Table 4. Factor loadings for the one-, two- and three-factor models.

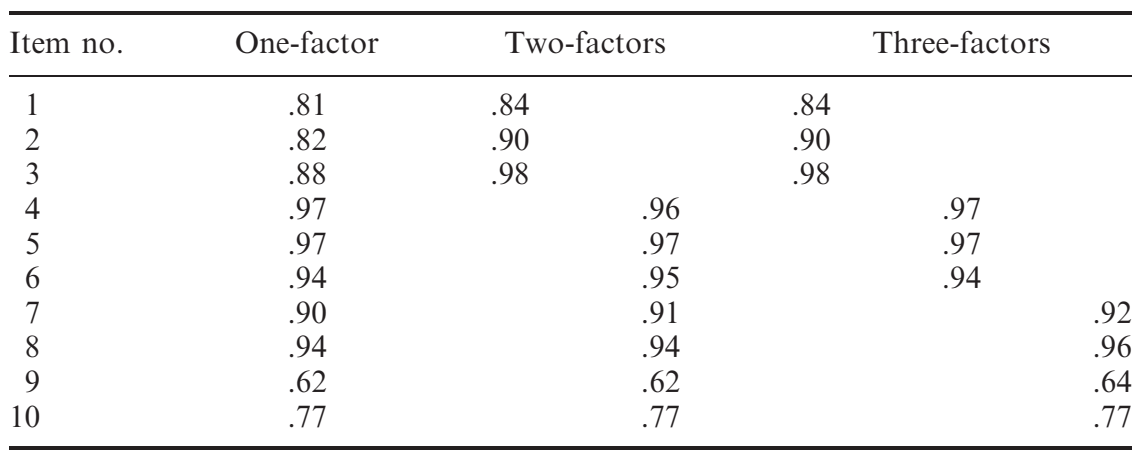


(.62-.98). There was a greater loading of the first three 'consumption' items on both the two- and three-factor models when compared to the singlefactor model. Very little difference emerged between the two- and threefactor structures, with marginally higher loadings on the latter for some items. The correlation between factors in the two-factor model was .89 and all coefficients were statistically significant. With regard to the three-factor model, the correlation between the first and second factors was .89; the correlation between the first and third factors was .86, whilst the correlation between the second and third factors was .98 .

\section{Discussion}

Overall, the information derived from the AUDIT indicates alarmingly high levels of harmful alcohol use amongst the MDOs in this study, with an average total score at 20.2. This is much higher when compared to other samples recruited from the general population in Britain $(M=5.7$; Shevlin $\&$ Smith, 2007) and Switzerland ( $M=4.76$; Gmel et al., 2001), as well as a sample of patients attending a General Practitioner clinic in Germany $(M=5.12$; Rist et al., 2009). However, the results are consistent with a small pool of research which shows a markedly higher incidence of alcohol use disorders amongst MDOs than in the general population (Cuffel, 1992; Fowler, Varr, Carter, \& Lewin, 1998; Regier et al., 1990). As in the results of previous work, albeit based on smaller sample sizes, most offenders were typically white, unemployed males in their early 30 s, a significant proportion of whom was homeless (McGilloway \& Donnelly, 2004).

It is interesting to note that most of the offenders in this study appeared to be falling into a repetitive pattern of unemployment, homelessness, substance abuse, crime and incarceration. The fact that those who were homeless also tended to have significantly higher AUDIT scores than their housed counterparts, suggests a strong link between alcohol abuse, mental health problems, homelessness and crime. For instance, over $70 \%$ of homeless people in Dublin abuse alcohol, $55 \%$ have been in prison whilst $30 \%$ have been diagnosed with a mental health problem (Lawless \& Corr, 2005). An extensive survey by the Bureau of Justice Statistics (2006) in America also showed that $18 \%$ of state prisoners, $14 \%$ of jail inmates and $10 \%$ of federal prisoners reported that they had used prescribed medication for a mental health problem during the year before arrest, or since entry to the CJS. The figures further show that these MDOs have higher average levels of alcohol abuse, homelessness, prior convictions and unemployment than prisoners with no mental ill health. As might be expected, those offenders in the current study whose crimes involved alcohol, obtained significantly higher AUDIT scores than those who committed non alcoholrelated offences; this provides good evidence for the construct validity of the measure. 
Whilst the above information provides a useful and interesting context for the current study, the principal aim of this work was to identify the factor structure of the AUDIT when administered to a large community-based sample of MDOs. The results support the suitability of both a two- (items 1-3 alcohol consumption and items 4-10 dependence/consequences) and threefactor (items 1-3 consumption, items 4-6 dependence and items 7-10 consequences) structure for the AUDIT. There is little support for a onefactor solution in view of the fit indices and given that all items of the 'consumption' factor loaded more heavily on both the two- and three-factor solutions. In addition, the correlation of .89 between the first and second factors shows a strong relationship, yet allows for a distinction between the factors. Thus, the best solution would appear to be a two-factor structure with an added error covariance between items 9 and 10. There was little difference between the two-factor and three-factor models, although the former is a more parsimonious option according to the PGFI (Mulaik et al., 1989). Additionally, the very high correlation between factors two and three in the three-factor solution, suggests that these have much in common, thereby supporting their combination.

These results appear to contradict the author's hypothesised model where factors two and three are considered as separate constructs (Saunders et al., 1993). However, they are consistent with most other studies that have examined the factor structure of the AUDIT. For example, Doyle et al. (2007) utilised datasets from two clinical populations (participating in alcohol intervention programmes) as well as archival data from five published studies on the AUDIT. Overall, they concluded that, despite evidence supporting both a two and three-factor solution, the two-factor solution (alcohol consumption: items 1-3 and alcohol-related consequences: items 4-10) was 'distinct and more parsimonious' (p. 477). Likewise, a number of other studies have concluded that, whilst a three-factor solution is a good fit, a two-factor solution again is more parsimonious (Chung, Colby, Barnett, \& Monti, 2002; Karno et al., 2000; Kelly \& Donovan, 2001; Lima et al., 2005; Maisto et al., 2000; Medina-Mora et al., 1998; O'Hare \& Sherrer, 1999; Shevlin \& Smith, 2007; Shields et al., 2004). Thus, the weight of evidence, to date, appears to support a two-factor solution across a diverse range of sample groups.

Despite the evidence in favour of a two-factor structure, there is a small body of research which proposes alternative factor solutions, including two studies that have identified a single factor for the AUDIT. For example, ElBassel et al. (1998) found that a single factor saturated the AUDIT in a study conducted with 400 American women who were incarcerated and classified as drug dependent. However, this study was based on a principal components analysis which may limit the extent to which a meaningful comparison can be made with the current study. Likewise, another US-based study by Skipsey et al. (1997) - involving a sample of 82 inpatients in a 
substance use rehabilitation programme - identified a single factor dominating the AUDIT. Over half of this sample (53\%) met the criteria for both drug and alcohol dependence.

More recently, a study by Rist et al. (2009) provided support for the authors' intended factor structure using a sample of German primary care patients $(n=6259)$. They concluded that a three-factor structure was a superior fit to the one- and two-factor alternatives. However, it must be noted that item 6 - investigating the frequency of drinking on the morning after a 'heavy drinking session' - was removed from the analysis due to very low frequency of responses $(<1 \%, 56 / 6259)$ and several other answer categories had to be combined for the same reason. Gmel et al. (2001) also found that the three-factor model was a better fit than a single factor for a large sample of people $(n=10,321)$ recruited from the general population in Switzerland. Although these authors noted that factors two and three were highly correlated, they did not investigate a two-factor model.

Thus, whilst acknowledging the support for a two-factor structure to the AUDIT, it would be premature perhaps, to completely dismiss alternative solutions. In the current study and others, there is a very fine line of interpretation between a two- and three-factor solution. Thus, the fit indices, in most cases, are comparable to the extent that the decision is made largely on the basis of the high correlations between factors two and three; that is, .98 in the current study, .94 in Shevlin and Smith (2007), .94 in the COMBINE study sample and .99 for the MATCH sample (Doyle et al., 2007). This correlation was slightly lower in the study by Rist et al. (2009) (.84) who argued for a three-factor solution, as did Gmel et al. (2001) (without testing for a two-factor solution) who noted correlations of .96 and .88 in German and French/Italian speaking samples, respectively. It should also be noted that the same three factors emerged as a suitable fit for the current MDO sample despite exceptionally high AUDIT scores and substantial inter-item correlations. Arguably therefore, it may be possible to separate the three constructs on a theoretical level alone, thereby confirming the original intention of Saunders et al. (1993) to capture abuse and dependence facets. However, the correlation of .98 between factors two and three cannot be ignored at a practical level and clearly shows a strong convergence, thereby supporting their combination.

These findings indicate an inherent difficulty in successfully replicating results using factor analytical techniques (Kline, 1994). However, they may also suggest, in line with the contention by several authors (e.g. Allen, Litten, Fertig, \& Babor, 1997; Karno et al., 2000), that a better understanding of the factor structure of the AUDIT can only be reached by carefully considering the method of factor analysis and the specific characteristics of the sample involved (e.g. severity of alcohol problems, gender and culture). 
From a practical point of view, there are implications for treating the AUDIT as uni-dimensional or multi-dimensional. From the current data, a fairly clear distinction emerged between the first three items (consumption) and the remainder of the scale (consequences). Thus, it might be useful to explore whether this distinction may allow for the use of the first factor only (i.e. the AUDIT-C) as a simpler and more efficient measure of alcohol consumption in clinical settings, as reported by a number of authors (Bradley et al., 2006; Bush, Kivlahan, McDonell, Fihn, \& Bradley, 1998; Dawson, Grant, Stinson, \& Zhou, 2005; Kaarne, Aalto, Kuokanen, \& Seppa, 2010). Large numbers of MDOs are constantly entering and moving through the judicial system, so a reduction in screening time might be beneficial within the context of the Belfast-based and other similar schemes, as well as addressing issues such as illiteracy. The benefits and drawbacks of reducing the scale in this way, from a measure of alcohol use disorders to alcohol consumption alone, would require careful consideration, particularly given that high levels of consumption may occur without dependence or adverse consequences (Chung et al., 2002), thereby limiting the information drawn, and assumptions made from the AUDIT-C.

Our findings also show that items 9 and 10 performed least well, overall, in terms of data fit for all models. One explanation may be that an additional factor could explain these items. In the original article describing the construction of the AUDIT, Saunders et al. (1993) refer to four categories of questions; that is, items 1-3 measure consumption, 4-6 drinking behaviour, 7-8 adverse reactions and 9-10 alcohol-related problems. However, the final version of the questionnaire combined questions 7-10 into one factor. Doyle et al. (2007), in the two original datasets they analysed, also noted a lack of cohesion between items 9 and 10 and the other five items in the 'alcohol-related consequences' factor (questions 4-10). However, they consider this to be most likely due to 'distributional problems' rather than a 'lack of construct similarity' (Doyle et al., 2007, p. 476). This may merit further investigation in order to ascertain the significance, or otherwise of these items for the overall validity of the AUDIT.

This point also raises questions as to the suitability of the alternate threepoint Likert scale on items 9 and 10 (i.e. score responses of 0, 2 and 4 vs. 0 , $1,2,3$ and 4 on all other items) and how this may affect the cohesion of the factor structure. It would be worth exploring whether a more suitable factor structure would emerge if items 9 and 10 were scored in line with all other items on the scale. However, it is difficult to suggest valid alternatives to the existing responses $(0-$ never, 2 - yes, but not in the last year and 3 -yes, in the last year). A similar response set to other items (i.e. 0 - never, 1 - less than monthly, 2 - monthly, 3 - weekly and 4 - daily) would be unsuitable as this would likely yield a negatively skewed, low scoring pattern given the 
nature of the questions. In addition, the responses to items 9 and 10, unlike the others, refer to a time scale beyond 'the last year'. This format may not be suitable for this population because such information may be prone to recall bias, especially where excessive alcohol intake may have impaired longer term memory. For example, as shown in Table 1, the items relating to more than a year previously were endorsed less than the other items $(13 \%$ and $7 \%$ ).

The current study was limited by a lack of control over the effects of drug abuse/addiction which may have impaired judgement, or influenced scoring on the AUDIT, thereby potentially distorting responses. Likewise, the extremely high average score for this group of MDOs, as well as evidence of intoxication in some cases during the screening phase, must also be kept in mind when interpreting or comparing the results reported here. It is also important to note the limitations of the CFA method, in that the extent to which CFA can test a theory or a structural set of variables is dependent upon the original theory underpinning a measure, the quality and nature of the data (including the possibility of non-linear relationships between variables) and the sample size. A further limitation relates to the fact that it was not possible within the resources of the study to undertake a formal psychiatric assessment. Diagnostic categories were assigned by the nurse and, for example, $21 \%$ of the sample had an unspecified alcohol disorder. It is important to bear this in mind when interpreting the findings and when considering the comparability of this sample with those in other similar studies. A final limitation was the unavailability of information on the number of MDOs who refused to take part in the screening; without this information, it is difficult to be clear about the representativeness of the sample.

However, the findings are based on a large sample size as well as a unique population subgroup with markedly high levels of hazardous drinking. The results also demonstrate a level of internal consistency that is higher than in most other studies. Our study adds to the limited, but growing research on the psychometric status of the AUDIT and associated issues, whilst also making an important contribution to the ongoing debate as to whether a one-, two- or three-factor structure is best suited to this instrument. The current uncertainty around this may be due to the overall performance of the scale with different populations and/or the inherent difficulty in neatly categorising the varied and complex patterns of human drinking behaviour. However, further work is needed to examine the links between sample characteristics, methods of analysis and the emergent factor structure of the AUDIT. Nonetheless, the instrument would appear to perform well across a wide range of severity including the typically high levels seen in the current MDO sample. Overall, the results suggest some potentially useful avenues for further research into the potential effects of culture, gender, social status, etc. on the factor structure, validity and 
reliability of the AUDIT, as well as a more thorough analysis of the characteristics and drinking patterns of the general offender population.

\section{References}

Allen, J.P., Litten, R.Z., Fertig, J.B., \& Babor, T. (1997). A review of research on the Alcohol Use Disorders Identification Test (AUDIT). Alcoholism - Clinical and Experimental Research, 21, 613-619.

Babor, T.F., de la Fuente, J.R., Saunders, J., \& Grant, M. (1992). AUDIT: The Alcohol Use Disorders Identification Test: Guidelines for use in primary health care. Geneva: World Health Organisation.

Bentler, P.M. (1990). Comparative Fit Indexes in structural models. Psychological Bulletin, 107, 238-246.

Brabins, C.J., \& Travers, R.F. (1994). Mental disorder amongst defendants in Liverpool Magistrates Court. Medicine, Science and the Law, 34, 279-283.

Bradley, K.A., Williams, E.C., Achtmeyer, C.E., Volpp, B., Collins, B.J., \& Kivlahan, D.R. (2006). Implementation of evidence-based alcohol screening in the Veterans Health Administration. American Journal of Managed Care, 12, 597-606.

Bush, K., Kivlahan, D.R., McDonell, M.B., Fihn, S.D., \& Bradley, K.A. (1998). The AUDIT alcohol consumption questions (AUDIT-C): An effective brief screening test for problem drinking. Archives of Internal Medicine, 158, 1789-1795.

Chung, T., Colby, S.M., Barnett, N.P., \& Monti, P.M. (2002). Alcohol Use Disorders Identification Test: Factor structure in an adolescent emergency department sample. Alcoholism - Clinical and Experimental Research, 26, 223-231.

Cohen, J. (1992). A power primer. Psychological Bulletin, 112, 155-159.

Cuffel, B.J. (1992). Prevalence estimates of substance abuse in schizophrenia and their correlates. Journal of Mental Disease, 180, 589-592.

Dawson, D.A., Grant, B.F., Stinson, F.S., \& Zhou, Y. (2005). Effectiveness of the derived Alcohol Use Disorders Identification Test (AUDIT-C) in screening for alcohol use disorders and risk-drinking in the US general population. Alcoholism - Clinical and Experimental Research, 29, 844-854.

Doyle, S.R., Donovan, D.M., \& Kivlahan, D.R. (2007). The factor structure of the Alcohol Use Disorders Identification Test (AUDIT). Journal of Studies on Alcohol and Drugs, 68, 474-479.

El-Bassel, N., Schilling, R., Ivanoff, A., Chen, D.-R., \& Hanson, M. (1998). Assessing the World Health Organisation's Alcohol Use Disorder Identification Test among incarcerated women. Journal of Offender Rehabilitation, 26, 71-89.

Fowler, I.L., Varr, V.J., Carter, N.T., \& Lewin, T.J. (1998). Patterns of current and lifetime substance use in schizophrenia. Schizophrenia Bulletin, 24, 443-445.

Gmel, G., Heeb, J.-L., \& Rehm, J. (2001). Is frequency of drinking an indicator of problem drinking? A psychometric analysis of a modified version of the Alcohol Use Disorders Identification Test in Switzerland. Drug and Alcohol Dependence, 64, 151-163.

Hillis, G. (1993). Birmingham Diversion Services. UK: Report to the Forensic Services Management team of Reaside Clinic.

Hoyle, R.H., \& Panter, A.T. (1995). Writing about structural equation models. In R.H. Hoyle (Ed.), Structural equation modelling: Concepts issues and applications (pp. 158-176). London: Sage.

Hu, L., \& Bentler, P.M. (1998). Fit indices in covariance structure modeling: Sensitivity to underparameterized model misspecification. Psychological Methods, 4, 424-453. 
Hu, L., \& Bentler, P.M. (1999). Cut-off criteria for fit indexes in covariance structure analysis: Conventional criteria versus new alternatives. Structural Equation Modeling, 6, 1-55.

Jöreskog, K.G., \& Sörbom, D. (1981). LISREL V: Analysis of linear structural relationships by the method of maximum likelihood. Chicago: National Educational Resources.

Jöreskog, K.G., \& Sörbom, D. (1993). Structural equation modelling with the SIMPLIS command language. Chicago: Scientific Software International.

Jöreskog, K.G., \& Sörbom, D. (2001). LISREL 8: User's reference guide. Chicago: Scientific Software International.

Jöreskog, K.G., \& Sörbom, D. (2006). LISREL 8.80 for Windows [Computer Software]. Lincolnwood, IL: Scientific Software International.

Kaarne, T., Aalto, M., Kuokanen, M., \& Seppa, K. (2010). AUDIT-C, AUDIT 3 and AUDIT-QF in screening risky drinking among Finnish occupational healthcare patients. Drug and Alcohol Review, 29, 563-567.

Karno, M., Granholm, E., \& Lin, A. (2000). Factor structure of the Alcohol Use Disorders Identification Test (AUDIT) in a mental health clinic sample. Journal of Studies on Alcohol, 61, 751-758.

Kelly, T.M., \& Donovan, J.E. (2001). Confirmatory factor analyses of the Alcohol Use Disorders Identification Test (AUDIT) among adolescents treated in Emergency Departments. Journal of Studies on Alcohol, 62, 838-842.

Kerner, H.J., Weitekamp, E.G.M., Stelly, W., \& Thomas, J. (2006). Patterns of alcoholism and criminality: Results of the Tuebingen Criminal Development Behaviour Study. Criminal Behaviour and Mental Health, 7, 401-420.

Kline, P. (1994). An easy guide to factor analysis. London: Routledge.

Lawless, M., \& Corr, C. (2005). Drug use among the homeless population in Ireland. Dublin: National Advisory Committee on Drugs.

Lima, C.T., Freire, A.C.C., Silva, A.P.B., Maia Teixeira, R., Farrell, M., \& Prince, M. (2005). Concurrent and construct validity of the AUDIT in an urban Brazilian sample. Alcohol and Alcoholism, 40, 584-589.

Maisto, S.A., Conigliaro, J., McNeil, M., Kraemer, K., \& Kelly, M.E. (2000). An empirical investigation of the Factor Structure of the AUDIT. Psychological Assessment, 12, 346-353.

McGilloway, S., \& Donnelly, M. (2004). Mental illness in the UK criminal justice system: A police liaison scheme for Mentally Disordered Offenders in Belfast. Journal of Mental Health, 13, 263-275.

Medina-Mora, E., Carreno, S., \& De la Fuente, J.R. (1998). Experiences with the Alcohol Use Disorders Identification Test (AUDIT) in Mexico. In M. Galanter (Ed.), Recent developments in alcoholism, Vol 14, the consequences of alcoholism (pp. 383-396). New York: Plenum Press.

Mulaik, S., James, L., Van Alstine, J., Bennet, N., Lind, S., \& Stilwell, C. (1989). An evaluation of goodness of fit indices for structural equation models. Psychological Bulletin, 105, 430-445.

O'Brien, T., \& Forman, A. (1994). The short term support to the diversion services and the Birmingham prison mental health screening programme. UK: Report to the Forensic Management Team of Reaside Clinic.

O'Hare, T., \& Sherrer, M.V. (1999). Validating the Alcohol Use Disorders Identification Test with college first-offenders. Journal of Substance Abuse Treatment, 17, $113-119$.

Overall, J.E., \& Gorham, D.R. (1962). The Brief Psychiatric Rating Scale. Psychological Reports, 10, 799-812.

Pallant, J. (2005). SPSS survival manual (2nd ed.). UK: Open University Press. 
Reed, J. (1992). Review of health and social services for mentally disordered offenders and others requiring similar services. London: HMSO.

Regier, D.A., Farmer, M.E., Rae, D.S., Locke, B.Z., Keith, S.J., Judd, L.L., \& Goodwin, F.K. (1990). Comorbidity of mental disorders with alcohol and other drug abuse. Journal of the American Medical Association, 264, 2511-2518.

Rist, F., Glöckner-Rist, A., \& Demmel, R. (2009). The Alcohol Use Disorders Identification Test revisited: Establishing its structure using nonlinear factor analysis and identifying subgroups of respondents using latent class factor analysis. Drug and Alcohol Dependence, 100, 71-82.

Saunders, J.B., Aasland, O.G., Babor, T.F., De La Fuente, J.R., \& Grant, M. (1993). Development of the Alcohol Use Disorders Identification Test (AUDIT): WHO Collaborative project on early detection of persons with harmful alcohol consumption-II. Addiction, 88, 791-804.

Shevlin, M., \& Smith, G.W. (2007). The factor structure and the concurrent validity of the Alcohol Use Disorders Identification Test based on a nationally representative UK sample. Alcohol and Alcoholism, 42, 582-587.

Shields, A.L., Guttmanova, K., \& Caruso, J.C. (2004). An examination of the factor structure of the Alcohol Use Disorders Identification Test in two high-risk samples. Substance Use \& Misuse, 39, 1161-1182.

Skipsey, K., Burleson, J.A., \& Kranzler, H.R. (1997). Utility of the AUDIT for identification of hazardous or harmful drinking in drug-dependent patients. Drug and Alcohol Dependence, 45, 157-163.

SPSS for Windows (version 13.0). Chicago: SPSS Inc.

Steiger, J.H. (1990). Structural model evaluation and modification: An interval estimation approach. Multivariate Behavioural Research, 25, 173-180.

Tanaka, J.S., \& Huba, G.J. (1989). A general coefficient of determination for covariance structure models under arbitrary GLS estimation. British Journal of Mathematical and Statistical Psychology, 42, 233-239.

The Bureau of Justice Statistics. (2006). Mental health problems of prison and jail inmates. Washington, DC: US Department of Justice. 
P. Hallinan et al.

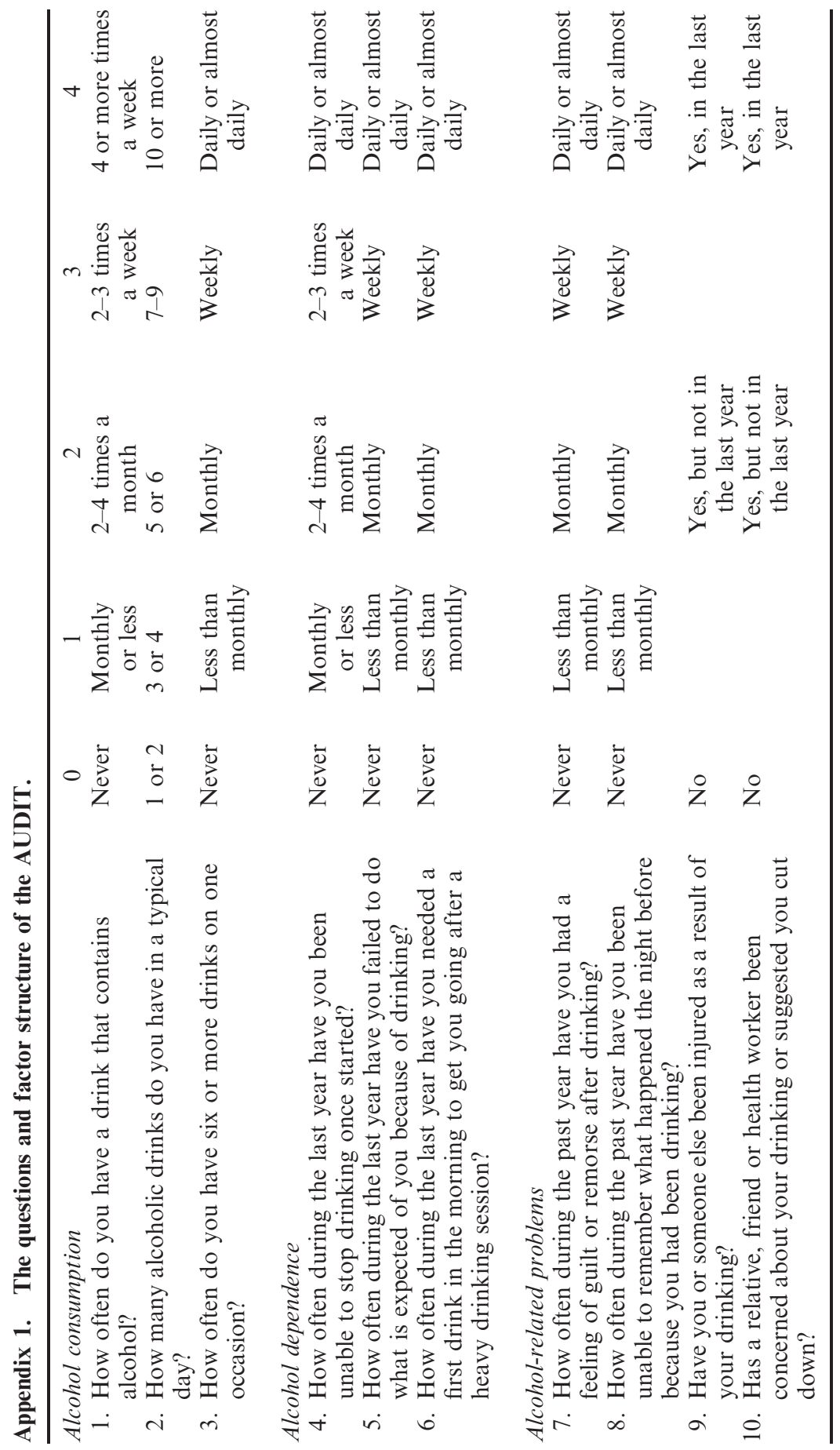

